\title{
Uji Perbandingan Kekuatan Kompresi Tumpatan Resin Komposit dengan Teknik Incremental Horizontal dan Teknik Bulk
}

\author{
Claudya Mundung \\ Vonny N. S. Wowor \\ Dinar A. Wicaksono
Program Studi Pendidikan Dokter Gigi Fakultas Kedokteran
Universitas Sam Ratulangi Manado
Email: claudyamundung44@gmail.com

\begin{abstract}
Composite resin is one of the restoration material used in dental practice. Its strength and resistance factors toward usage and stability dimension lead to high compression strength to withstand mastication burden. This capacity has to be considered in choosing the composite resin as restoration material. This study was aimed to compare the compression strength of resin composites formed with horizontal incremental restoration technique and with bulk restoration technique. This was an experimental study conducted at Material Engineering Laboratory of the Faculty of Engineering Sam Ratulangi University Manado. There were six samples divided into 2 groups, each of 3 samples. The results showed that compression strength of resin composite formed with horizontal incremental technique was 199.45 MPa meanwhile of resin composite formed with bulk technique was 191.65 MPa. Conclusion: Compression strength of resin composite formed with horizontal incremental technique was higher than of resin composite formed with bulk technique.
\end{abstract}

Keywords: resin composite, compression strength, incremental technique, bulk technique

\begin{abstract}
Abstrak: Resin komposit merupakan salah satu bahan restorasi yang sering digunakan di kedokteran gigi. Faktor kekuatan dan ketahanan terhadap penggunaan dan stabilitas dimensi memungkinkannya memiliki kekuatan kompresi yang besar untuk menahan beban kunyah. Hal ini merupakan salah satu keunggulan yang menjadi dasar pertimbangan saat memilih resin komposit sebagai bahan tumpatan. Penelitian ini bertujuan untuk mengetahui perbandingan teknik penumpatan incremental horizontal dan teknik penumpatan bulk untuk kekuatan kompresi resin komposit. Jenis penelitian ialah eksperimental yang dilakukan di Laboratorium Rekayasa Material Fakultas Teknik Universitas Sam Ratulangi. Sampel berjumlah 6 buah dibagi menjadi 2 kelompok, masing-masing terdiri dari 3 sampel. Hasil penelitian menunjukkan bahwa kekuatan kompresi tumpatan resin komposit dengan teknik incremental horizontal sebesar 199,45 MPa dan tumpatan resin komposit dengan teknik bulk sebesar 191,65 MPa. Simpulan: Kekuatan tekanan kompresi tumpatan resin komposit menggunakan teknik incremental horizontal lebih tinggi dibandingkan dengan menggunakan teknik bulk.

Kata kunci: resin komposit, kekuatan kompresi, teknik penumpatan incremental horizontal, teknik penumpatan bulk
\end{abstract}

Penggunaan resin komposit sering dibandingkan dengan bahan tumpatan lainnya karena merupakan bahan tumpatan yang memiliki warna serupa dengan gigi dan memiliki kestabilan warna. ${ }^{1}$ Faktor kekuatan dan ketahanan terhadap penggunaan dan stabilitas dimensi memungkinkannya memiliki kekuatan kompresi yang besar untuk menahan beban kunyah. Hal ini merupakan salah satu keunggulan yang menjadi dasar pertimbangan saat memilih resin komposit sebagai bahan tumpatan. Resin komposit 
yang banyak digunakan saat ini yaitu resin komposit yang diaktifkan dengan bantuan visible light cure (VLC). ${ }^{2}$

Salah satu cara untuk meningkatkan kekuatan resin komposit ialah teknik yang digunakan saat proses penumpatan. ${ }^{3}$ Terdapat dua teknik penumpatan resin komposit yaitu teknik incremental horizontal dan teknik bulk. Teknik incremental horizontal digunakan sebagai standar karena dapat mencegah pembentukan celah yang diakibatkan oleh tekanan pada saat polimerisasi dan dapat menghasilkan ikatan yang lebih baik antara resin komposit dan jaringan gigi. ${ }^{4}$ Teknik incrementtal horizontal termasuk teknik yang sulit sehingga teknik bulk sering dipilih karena waktu yang lebih efisien dengan aplikasi penumpatan bahan resin komposit secara sekaligus ke dalam kavitas satu kali tumpatan kemudian dilanjutkan dengan penyinaran. ${ }^{5}$

Ketahanan internal dari suatu benda untuk menahan beban disebut kekuatan kompresi. ${ }^{6}$ Kekuatan kompresi suatu bahan dapat diketahui melalui suatu pengujian, demikian halnya dengan kekuatan kompresi tumpatan resin komposit. ${ }^{7}$ Kekuatan kompresi yang lebih baik dimiliki oleh resin komposit yang merupakan salah satu alasan resin komposit dipilih untuk digunakan pada penumpatan gigi anterior dan posterior. Penelitian ini bertujuan untuk mengetahui perbandingan kekuatan kompresi tumpatan resin komposit dengan teknik incremental horisontal dan teknik bulk.

\section{BAHAN DAN METODE PENELITIAN}

Jenis penelitian ini ialah eksperimental. Penelitian dilakukan di Laboratorium Program Studi Pendidikan Dokter Gigi Fakultas Kedokteran Universitas Sam Ratulangi untuk pembuatan sampel penelitian dan di Laboratorium Struktur dan Material Bangunan Fakultas Teknik Universitas Sam Ratulangi untuk pengukuran kekuatan kompresi sampel.

Alat yang digunakan dalam penelitian ini terdiri dari: visible light curing unit (merk LA 500 Blue Light), glass plate, plastic filling instrument, pinset, spatula semen, alat tes kompresi (control digital), jangka sorong, timbangan digital, Petri disk, sarung tangan, jas lab, masker, kamera ponsel, kater, dan alat tulis. Bahan yang digunakan dalam penelitian ini berupa: Resin komposit A3.5 merk Filtex $Z$ 350 XT (3M ESPE), cotton pellet, sedotan berbahan plastik dengan diameter $5 \mathrm{~mm}$ dan tinggi $4 \mathrm{~mm}$.

Cetakan disiapkan dengan menggunakan sedotan berbahan plastik berdiameter 5 $\mathrm{mm}$ dan tinggi $4 \mathrm{~mm}$. Cetakan dibuat sebanyak 6 (enam) buah dan dibagi atas 2 kelompok, setiap kelompok terdiri dari 3 (tiga) buah cetakan.

Tahapan pembuatan sampel tumpatan dengan teknik incremental horizontal menggunakan cetakan sedotan yang telah dibuat sebelumnya. Resin komposit nanofill sebanyak 0,7 gr dimasukkan ke dalam cetakan dan dikondensasi, kemudian dilakukan penyinaran selama 20 detik. Kegiatan yang sama diulang kembali di atas lapisan pertama hingga terbentuk tumpatan yang terdiri dari 3 (tiga) lapisan resin komposit. Tumpatan dibuat sebanyak 3 (tiga) buah.

Tahapan pembuatan sampel tumpatan dengan teknik bulk menggunakan cetakan dari sedotan yang sudah dibuat sebelumnya. Resin komposit nanofill sebanyak 0,21 gr diaplikasikan ke dalam ruang cetakan dan dikondensasi serta dilakukan penyinaran selama 60 detik. Kegiatan yang sama diulang sehingga diperoleh 3 (tiga) buah tumpatan.

Tumpatan resin komposit yang sudah dibuat selanjutnya dikeluarkan dari cetakan dan dikelompokkan menurut teknik penumpatannya. Tumpatan resin komposit kemudian diletakkan dalam Petri disk dan dibawa ke Laboratorium Struktur dan Matrial Bangunan Fakultas Teknik Universitas Sam Ratulangi untuk dilakukan pengukuran kekuatan kompresi dengan menggunakan alat tes kompresi digital yang angka dan nilainya langsung bisa terlihat pada skala dalam satuan Mega Pascal (MPa) yang tertera pada alat uji kompresi.

Data penelitian diperoleh dari hasil pengukuran kekuatan kompresi tumpatan resin komposit dengan teknik incremental 
horizontal dan teknik bulk menggunakan alat test kompresi digital. Data hasil penelitian dihitung secara manual, kemudian dimasukkan ke dalam tabel distribusi frekuensi untuk selanjutnya dianalisis perbandingan hasil uji kompresi tumpatan resin komposit dengan teknik incremental horizontal dan teknik bulk. Uji normalitas data menggunakan uji Shapiro-Wilk dan uji komparasi menggunakan uji-t, dan bila data tidak terdistribusi normal menggunakani independent $t$-test.

\section{HASIL PENELITIAN}

Tabel 1 menunjukkan bahwa hasil uji kekuatan kompresi tumpatan resin komposit dengan teknik incremental horizontal yaitu pada cetakan pertama sebesar 196,22 $\mathrm{MPa}$; hasil tumpatan resin komposit kedua sebesar 197,84 MPa; sedangkan tumpatan resin komposit ketiga sebesar 204,30 MPa.

Tabel 1. Distribusi hasil uji kekuatan kompresi tumpatan resin komposit dengan teknik incremental horizontal dalam satuan Mega Pascal (MPa)

\begin{tabular}{cc}
\hline $\begin{array}{c}\text { Cetakan resin } \\
\text { komposit }\end{array}$ & $\begin{array}{c}\text { Hasil uji kekuatan } \\
\text { kompresi (MPa) }\end{array}$ \\
\hline 1 & 196,22 \\
2 & 197,84 \\
3 & 204,30 \\
Rerata & 199,45 \\
\hline
\end{tabular}

Tabel 2 menunjukkan bahwa hasil uji kekuatan kompresi tumpatan resin komposit dengan teknik bulk yaitu pada cetakan pertama sebesar 190,57 MPa; hasil tumpatan resin komposit kedua sebesar 191,38 $\mathrm{MPa}$; sedangkan tumpatan resin komposit ketiga sebesar 192,99 $\mathrm{MPa}$.

Tabel 2. Distribusi hasil uji kekuatan kompresi tumpatan resin komposit dengan teknik bulk dalam satuan Mega Pascal (MPa)

\begin{tabular}{cc}
\hline $\begin{array}{c}\text { Cetakan resin } \\
\text { komposit }\end{array}$ & $\begin{array}{c}\text { Hasil uji kekuatan } \\
\text { kompresi (MPa) }\end{array}$ \\
\hline 1 & 190,57 \\
2 & 191,38 \\
3 & 192,99 \\
Rerata & 191,65 \\
\hline
\end{tabular}

Tabel 3 menunjukkan bahwa rerata hasil uji kekuatan kompresi tumpatan resin komposit dengan teknik incremental horizontal memiliki kekuatan kompresi sebesar 199,45 MPa, lebih besar dibandingkan dengan teknik bulk kekuatan kompresi sebesar 191,65 MPa.

Tabel 3. Distribusi rerata hasil uji kekuatan kompresi tumpatan resin komposit dengan teknik incremental horizontal dan teknik bulk dalam satuan Mega Pascal (MPa)

\begin{tabular}{cc}
\hline $\begin{array}{c}\text { Teknik } \\
\text { penumpatan }\end{array}$ & $\begin{array}{c}\text { Rerata hasil uji kekuatan } \\
\text { kompresi resin komposit } \\
\text { (MPa) }\end{array}$ \\
\hline $\begin{array}{c}\text { Incremental } \\
\text { horizontal } \\
\text { Bulk }\end{array}$ & 199,45 \\
\hline
\end{tabular}

Tabel 4 memperlihatkan hasil uji normalitas data terhadap kekuatan kompresi menggunakan uji Shapiro-Wilk dan dilanjutkan dengan uji Mann-Withney yang ditampilkan pada Tabel 5.

Tabel 4. Uji normalitas Shapiro-Wilk terhadap kekuatan kompresi resin komposit dengan teknik incremental horizontal dan teknik bulk

\begin{tabular}{ccccc}
\hline \multirow{2}{*}{ Kelompok } & \multicolumn{3}{c}{ Shapiro-Wilk } \\
\cline { 2 - 5 } & Statistic & Df & Sig. \\
\hline Hasil $\begin{array}{c}\text { Teknik } \\
\text { incremental } \\
\text { horizontal } \\
\text { Teknik } \\
\text { bulk }\end{array}$ & 0,893 & 30 & 0,364 \\
& 0,965 & 30 & 0,640 \\
\hline
\end{tabular}

Tabel 5. Hasil uji statistik independent t-test

\begin{tabular}{cc}
\hline Teknik penumpatan & Sig. \\
\hline $\begin{array}{c}\text { Incremental horizontal } \\
\text { Bulk }\end{array}$ & 0,036 \\
\hline
\end{tabular}

\section{BAHASAN}

Kekuatan resin komposit dipengaruhi oleh lamanya penyinaran, proses penumpatan, ketebalan tumpatan, dan kemampuan sinar menembus ketebalan tumpatan. Penyinaran yang kurang dapat menghasilkan bahan yang lunak pada bagian dasar sehingga jarak ujung sinar harus diletakkan 
sedekat mungkin dengan permukaan tumpatan kurang lebih $1 \mathrm{~mm}$. Pemaparan yang lama dilakukan pada warna yang lebih gelap. $^{7}$

Pada penelitian ini bahan yang digunakan ialah resin komposit jenis nanofill yaitu Filtex Z 350 XT (3M ESPE). Resin komposit nanofill memiliki sifat mekanik yang baik, seperti kekuatan tekan, kekuatan tarik dan ketahanan terhadap fraktur yang tinggi. Resin komposit nanofill juga memiliki estetik yang baik sehingga resin jenis tersebut banyak digunakan oleh dokter gigi saat ini. ${ }^{8}$

Hasil uji kekuatan kompresi resin komposit dengan teknik penumpatan incremental horizontal memiliki nilai rerata kekuatan kompresi yang cukup tinggi yakni sebesar 199,45 MPa. Pada hasil penelitian yang dilakukan, sampel berjumlah 3 (tiga) tumpatan yaitu pada tumpatan pertama sebesar 196,22 MPa; tumpatan kedua sebesar 197,84 MPa; sedangkan tumpatan ketiga sebesar 204,30 MPa. Terdapat perbedaan kekuatan yang besar antara tumpatan pertama dan tumpatan ketiga. Penulis berasumsi bahwa hal tersebut dipengaruhi oleh jarak penyinaran. Proses polimerisasi terjadi saat penyinaran dilakukan, walaupun durasi lamanya penyinaran sama, namun jarak penyinaran berbeda. Kurangnya perhatian terhadap jarak penyinaran dapat menyebabkan adanya perbedaan yang cukup besar antara kemam-puan tumpatan resin komposit kesatu dan ketiga dalam menahan daya kompresi. Diasumsikan bahwa jarak penyinaran yang dilakukan dalam proses penumpatan berpengaruh pada kekuatan suatu bahan tumpatan, karena memengaruhi daya tembus sinar saat proses polimerisasi. Hal tersebut bisa mengakibatkan bahan tumpatan menjadi berkurang kekuatannya. ${ }^{9}$

Hasil uji kekuatan kompresi resin komposit dengan teknik penumpatan bulk memiliki nilai rerata kekuatan kompresi sebesar 191,65 MPa. Bila dibandingkan dengan rerata kekuatan kompresi resin komposit dengan teknik incremental horizontal, kekuatan kompresinya lebih kecil. Asumsi penulis ialah teknik bulk memiliki kekuatan kompresi yang lebih kecil karena teknik aplikasi bahan dengan cara sekali tumpat dan penyinaran yang dilakukan dalam satu waktu menyebabkan hasil polimerisasi kurang sempurna. Ketebalan bahan tumpatan resin komposit yang cukup tinggi walaupun disinari cukup lama, memengaruhi kekuatan kompresi tumpatan. Diduga hal ini diakibatkan daya tembus sinar menjadi kurang efektif dalam mencapai dasar tumpatan akibat ketebalan bahan sehingga polimerisasi menjadi kurang sempurna. Di samping itu rentan terjadinya pengerutan polimerisasi yang juga memengaruhi hasil. Menurut asumsi penulis, ketebalan tumpatan, jarak sinar dengan tumpatan resin komposit, serta lamanya penyinaran merupakan faktor-faktor yang mengakibatkan berkurangnya kekuatan kompresi tumpatan dengan teknik penumpatan bulk. ${ }^{8}$

Teknik incremental horizontal digunakan sebagai standar karena dapat mencegah pembentukan celah yang diakibatkan oleh tekanan pada saat polimeriasasi dan dapat menghasilkan ikatan yang lebih baik antara resin komposit dan jaringan gigi. ${ }^{4} \mathrm{Hal}$ ini sesuai dengan hasil penelitian oleh Katona dan Barrak yang menyatakan bahwa teknik incremental lebih disarankan karena polimerisasi lebih ideal. Penggunaan teknik incremental menghasilkan kekuatan tekan yang secara bermakna lebih tinggi pada resin komposit nanofill, sehingga teknik incremental direkomendasikan untuk kavitas yang dalam. ${ }^{10}$ Dari hasil penelitian yang dilakukan dapat dinyatakan bahwa kekuatan kompresi tumpatan resin komposit dipengaruhi oleh teknik penumpatan, ketebalan resin komposit, dan lamanya penyinaran mendapatkan polimerisasi yang baik yang dapat meningkatkan kekuatan kompresi resin komposit. ${ }^{8,9}$

Berdasarkan kedua hasil uji kekuatan kompresi resin komposit dengan teknik incremental horizontal dan teknik bulk tersebut didapatkan perbedaan kekuatan kompresi antara kedua jenis tumpatan resin komposit tersebut yang ditumpat dengan teknik penumpatan berbeda. 


\section{SIMPULAN}

Berdasarkan hasil penelitian ini dapat disimpulkan bahwa terdapat perbedaan kekuatan kompresi antara tumpatan resin komposit dengan teknik incremental horizontal dan tumpatan resin komposit dengan teknik bulk. Kekuatan kompresi tumpatan resin komposit dengan teknik incremental horizontal lebih tinggi dibandingkan tumpatan dengan teknik bulk

\section{SARAN}

Disarankan agar Dinas Kesehatan dan jajarannya di Puskesmas sosialisasi hasil penelitian kepada tenaga kesehatan gigi dan mulut di wilayah kerjanya sehingga dapat meningkatkan pengetahuan dan ketrampilan mereka dalam pemanfaatan tumpatan resin komposit secara efektif dan efisien yang berdampak pada efisiensi tenaga dan biaya pengobatan.

Bagi institusi pendidikan diharapkan dapat mendorong para mahasiswa untuk memanfaatkan hasil-hasil penelitian mahasiswa yang terdapat di perpustakaan untuk menambah dan memperluas wawasan pengetahuan mereka, termasuk pengetahuan tentang perbandingan kekuatan kompresi tumpatan resin komposit yang ditumpat dengan teknik yang berbeda.

Saat ini terdapat berbagai jenis bahan resin komposit yang digunakan sebagai bahan tumpatan sehingga disarankan untuk penelitian lanjut dengan cara yang sama namun dilakukan pada resin komposit dengan jenis yang berbeda.

\section{DAFTAR PUSTAKA}

1. Mukuan T. Gambaran kebocoran tepi tumpatan pasca restorasi komposit pada mahasiswa program studi kedokteran gigi angkatan 2005-2007. eG. 2013; 1(2):115-20.

2. Fahrini N. Pengaruh penambahan E-Glass fiber terhadap kekuatan kompresi resin komposit nanofill [Naskah Publikasi]. Surakarta: Universitas Muhammadiyah; 2016.

3. Susanto A. Pengaruh ketebalan bahan dan lamanya waktu penyinaran terhadap kekerasan permukaan resin komposit sinar. Majalah Kedokteran Gigi. 2005; 38(1):32-5.

4. Van Ende A, De Munck J, Van Landuyt KL, Poitevin A, Peumans M, Van Meerbeek B. Bulk filling of high Cfactor posterior cavities: effect on adhesion to cavity bottom dentin. Dent Matter. 2013;29(3):269-77.

5. Christensen GJ. Advantages and challenges of bulk-fill resins. Clinicians Report. 2012;5(1):1-6.

6. Roeroe VM, Wicaksono DA, Juliatri. Gambaran kekuatan tekanan bahan tumpatan semen ionomer kaca yang direndam dalam minuman beralkohol. eG. 2015;3(1).

7. Anusavice KJ. Buku Ajar Ilmu Bahan Kedokteran Gigi (10th ed). Jakarta: EGC, 2004; p. 228-49, 260-61.

8. Afsari IG. Perbedaan kekuatan tekan (compressive strength) resin komposit nano fill antara teknik inkremental dan teknik bulk fill [Publikasi Ilmiah]. Surakarta: Universitas Muhammadiyah; 2016.

9. Susanto AA. Pengaruh ketebalan bahan dan lamanya waktu penyinaran terhadap kekerasan permukaan resin komposit sinar. Maj Ked Gigi (Dent J). 2005; 38(1):32-35.

10. Yamazaki PC, Bedran-Russo AKB, Pereira, PNR, Swift JR. Microleakage evaluation of a new low shrinkage composite restorative material. Operative dentistry. 2006;31(6):670-6. 